\title{
On the Stationarity of Annual Precipitation over China (1959-2018) $\mathscr{O}$
}

\author{
HONG WANG \\ Key Laboratory of Water Cycle and Related Land Surface Processes, Institute of Geographic Sciences and \\ Natural Resources Research, Chinese Academy of Sciences, Beijing, China
}

\section{FUBAO SUN}

Key Laboratory of Water Cycle and Related Land Surface Processes, Institute of Geographic Sciences and Natural Resources Research, Chinese Academy of Sciences, Beijing, and State Key Laboratory of Desert and Oasis Ecology, Xinjiang Institute of Ecology and Geography, Chinese Academy of Sciences, Urumqi, and Akesu National Station of Observation and Research for Oasis Agro-ecosystem, Akesu, and College of Resources and Environment, University of Chinese Academy of Sciences, and Center for Water Resources Research, Chinese Academy of Sciences, Beijing, China

(Manuscript received 23 August 2019, in final form 18 March 2020)

\begin{abstract}
Stationarity is an assumption that permeates training and practice in water-resource engineering. However, with global change, the validity of stationarity as well as uncertainty of nonstationarity in water-resource planning are being questioned; thus, it is critical to evaluate the stationarity of climate variables, especially precipitation. Based on the continuous observation data of precipitation from 1427 stations across China, 593 efficient grid cells $\left(1^{\circ} \times 1^{\circ}\right)$ are constructed, and the annual precipitation stationarities from 1959 to 2018 are analyzed. The evaluated autocorrelation stationarity indicates that $92.24 \%-96.12 \%$ of the grid cells for an autocorrelation coefficient of lag 1-8 years of precipitation are indistinguishable from 0 [90\% confidence level (CL)]. The mean stationarity indicates that $97.47 \%$ of the grid cells have a stable mean for 30 years (90\% CL); beyond the confidence limits, they are mainly located in the northwest of China, where annual precipitation is less, and the average exceeding range is $\pm 3.78 \mathrm{~mm}$. The long-term observation of annual precipitation in Beijing (1819-2018) and Shanghai (1879-2018) also yields autocorrelation and mean stationarities. There is no significant difference in the annual precipitations between the past 20 years (1999-2018) and the past 60 years (19592018) over China. Therefore, the annual precipitation in China exhibits a weak stationary behavior that is indistinguishable from the stationary stochastic process. The average variation in precipitation is $\pm 9.55 \%$ between 30 successive years and $16.53 \%$ between 10 successive years. Therefore, it is valuable and feasible to utilize the historical data of annual precipitation as the basis of water-resources application.
\end{abstract}

\section{Introduction}

Stationarity is an assumption that natural systems fluctuate within an unchanging envelope of variability, and precipitation stationarity is an assumption that permeates training and practice in water-resource engineering (Burt et al. 2009; Khintchine 1934; Kolmogorov 1938; Koutsoyiannis and Montanari 2015; Milly et al. 2008; Montanari and Koutsoyiannis 2015; Nelson and

Supplemental information related to this paper is available at the Journals Online website: https://doi.org/10.1175/JHM-D-190195.s1.

Corresponding authors: Hong Wang, wanghong@igsnrr.ac.cn; Fubao Sun, sunfb@igsnrr.ac.cn
Matejcik 1995). Observation data of historical precipitation is an important basis for water resources planning, hydropower project construction, agricultural irrigation, social and economic development planning, and hydrological and climatic simulations (Benoit et al. 2018; Cordery et al. 2007; McCarl et al. 2008). To improve the reliability of the engineering design, it is necessary to analyze data from at least one climatic or hydrological time scale (approximately 30 years) (Arguez et al. 2012; Sun et al. 2018; WMO 2019), because the climate variables are considered as stationarity if the mean remains constant over the time scale (Arguez and Vose 2011; Griggs and Noguer 2002; Knox and Kundzewicz 1997; Sun et al. 2018). Moreover, the distribution density of observation stations must be guaranteed. 
However, with changes in climate and the underlying surface (e.g., land use, urbanization, dams, and water withdrawals), the stationarity of precipitation and water resources are being questioned (Milly et al. 2008, 2015; Richardson et al. 2018; Sadegh et al. 2016; Singh et al. 2016). In contrast, it has been asserted that stationarity is dead under currently changing climatic conditions and must no longer serve as a central and default assumption in water-resource risk assessment and planning (Milly et al. 2008, 2015). Nonstationarity implies a reduced representativity of experience (Montanari and Koutsoyiannis 2015) and data, and it is crucial to identify a suitable successor for planning human adaptation to changing climate (Milly et al. 2008, 2015). Some researchers believe that compared to climatic mechanisms, endogenous catchment mechanisms (e.g., groundwater table, baseflow, and vegetation) govern nonstationarity in rainfall-runoff relationships (Deb et al. 2019). Many studies have reported that nonstationarity of extreme precipitation and peak flow at subdaily and daily time scales (Dhakal et al. 2015; $\mathrm{Gu}$ et al. 2017; Jakob et al. 2011; Kharin et al. 2007; Lewis 2018; Prosdocimi et al. 2014; Seth and Sisson 2011; She et al. 2015; Uboldi and Lussana 2017). Extreme precipitation is expected to increase by $7 \%$ per degree of temperature at daily time scales and it exhibits a higher increasing rate at subdaily time scales (Wang et al. 2018).

In contrast, it has been argued that stationarity is always relevant and that there are time-invariant mechanisms in hydrological systems (Koutsoyiannis and Montanari 2015; Montanari and Koutsoyiannis 2015). Given that an unnecessary resort to nonstationarity may imply a reduction in predictive capabilities, a pragmatic approach, based on the exploitation of past experience and data, is a prerequisite for setting up mitigation policies for environmental risks (Montanari and Koutsoyiannis 2015). Some researchers (Murphy and Ellis 2014) have also reported that precipitation or runoff remain stationary processes and resolving trends amidst natural variability are unlikely to change for several decades. Results showed that approximately $76 \%$ of the annual precipitation over global land surface showed little or no change, indicating stationary behavior (Sun et al. 2018). At the same time, some results showed that the duration of extreme rainfall spells was found to be stationary but associated with nonstationarity intensity and frequency (Mondal and Mujumdar 2015). Hence, a methodology was developed that is able to differentiate watersheds that have undergone significant changes in land use, urbanization, and/or hydroclimatic conditions between stationarity and nonstationarity (Sadegh et al. 2016). Since stationarity is almost always a part of the composition of a time series (Matalas 2012), and an underlying assumption for many statistical procedures used in time series analysis, nonstationary results are often converted to stationary data in some cases (Benoit et al. 2018; Montanari and Koutsoyiannis 2015).

With environmental changes, the validity of stationaritybased water-resource planning is being questioned, while the uncertainty of nonstationary planning may be higher. Therefore, it is critical to identify the stationarity of climate variables, especially precipitation, for water-resource planning. Time series can be classified into strictly stationary and weakly stationary time series (Shumway and Stoffer 2011). A time series, wherein the probability function of all moments is constant over time is defined as strictly stationary or higher-order stationarity. A weakly stationary time series, also known as second-order stationary, is constant in regard to only mean and covariance functions. A weakly stationary test is considered sufficient to evaluate whether a time series is stationary or not and is widely used in practice (Murphy and Ellis 2014; Shumway and Stoffer 2000). This analysis is based on data from 1427 stations for continuous observation of precipitation from 1959 to 2018 over China; data from stations with longer observation are included to study the annual precipitation stationarity. In section 2, we describe the study data and methods. Section 3 reports the stationarity of the past 60 years, those for the longer period, and the variations in the past 20 years; this is followed by the conclusions of the study.

\section{Data and methods}

Figure 1 shows the 1473 meteorological stations that recorded precipitations daily without exception from 1959 to 2018 to analyze the stationary characteristics of annual precipitation in China. The data were obtained from meteorological stations of the China Meteorological Data Service Center (CMDC) (http:// data.cma.cn/). The precipitation was manually observed twice (0800 and 2000 local Beijing time) a day, and the daily precipitation was determined from the accumulated observation data from 2000 to 2000 local time. Rain gauge, tilling, and siphon rain gauge were the main instruments for observing precipitation. Daily precipitation above $0.1 \mathrm{~mm}$ is defined as a precipitation event. All data were checked for; suspicious and incorrect data were rechecked and rectified manually (CMDC) (http://data.cma.cn/). To minimize the statistical deviation caused by nonuniformity of the distribution of the stations, we defined the grid cells as having a spatial resolution of $1^{\circ} \times 1^{\circ}$ and identified the effective grid cells containing at least one station; 593 effective grid cells 


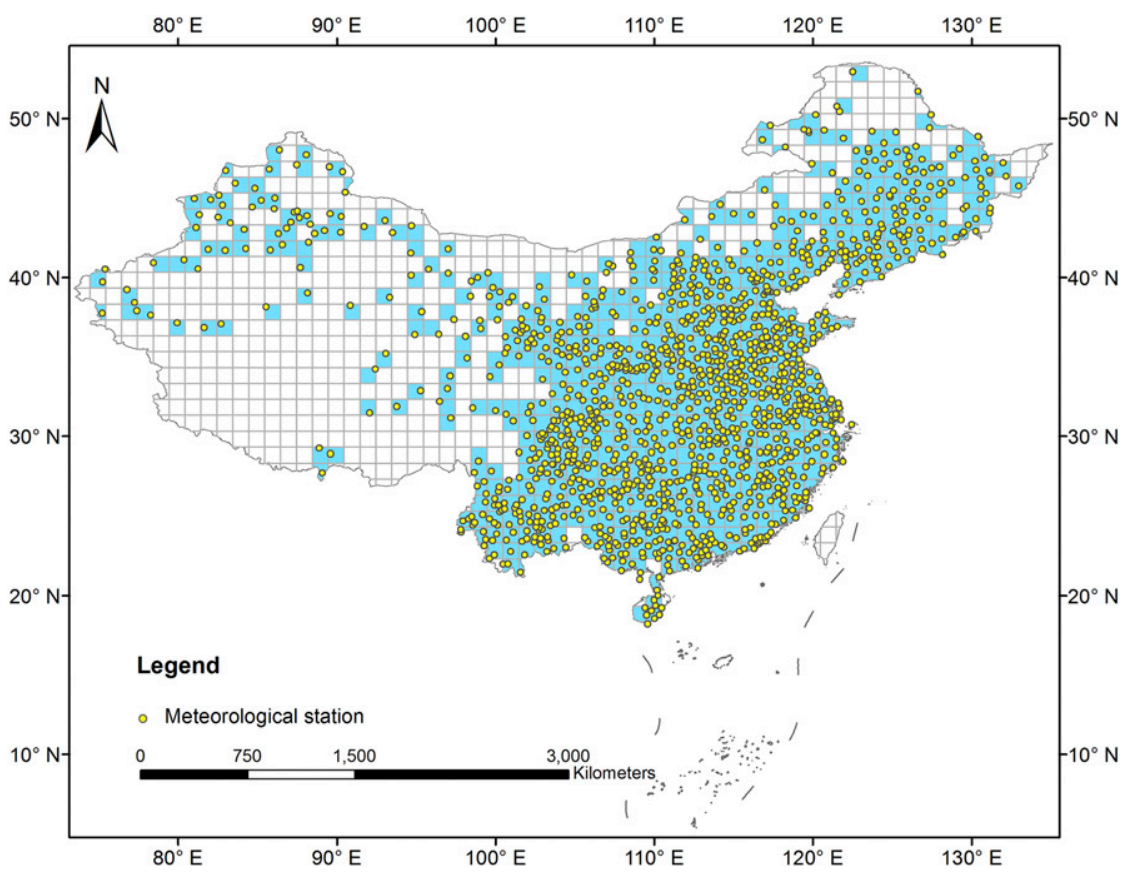

FIG. 1. The meteorological stations with daily data from 1959 to 2018 without exception over China and selected grid cells, containing at least one station each (spatial resolution of $\left.1^{\circ} \times 1^{\circ}\right)$.

were selected. For a grid containing more than one observation station, the average of the precipitation data collected from the relevant stations was used for calculation and analysis. The analysis results based on meteorological stations are also provided in the online supplemental material. Stationarity was analyzed by the mean and autocorrelation of annual precipitation time series according to the definition of weak stationarity. The method of stationarity analysis for precipitation was developed by Sun et al. (2018). Traditional statistical analyses were performed using SPSS (version 22) and Matlab (version R2015b). SigmaPlot 10 and ArcGIS 9.3 were used to perform geostatistical analyses and produce figures.

\section{Results and discussion}

\section{a. Autocorrelation stationarity of annual precipitation over China (1959-2018)}

We calculated the lag 1-8 autocorrelation coefficient of annual precipitation for each grid cell in 19592018. Figure 2 shows the autocorrelation with a $90 \%$ confidence level (CL). The $90 \%$ confidence limits for the autocorrelation $[= \pm(1.64 / \sqrt{60})]$ are \pm 0.212 , which are thresholds to distinguish grid cells that have lag autocorrelation indistinguishable from zero (blue cells in Fig. 2) from those showing positive (yellow) and negative (red) lag autocorrelation. Of the grid cells for a lag 1 autocorrelation coefficient (Fig. 2a), 92.24\% are within the $90 \%$ confidence interval (CI) and $93.76 \%-$ $96.12 \%$ for lags $2-8$. The results indicate that the autocorrelations of precipitation in China (1959-2018) are indistinguishable from 0 and their autocorrelation functions are independent of the specific time position. At the same time, the lag 1-8 autocorrelation coefficients based on meteorological stations are also provided in the supplemental material (Fig. S1). For lag 1-8 years of precipitation, $89.84 \%-94.39 \%$ of the stations are indistinguishable from 0 (90\% CL).

\section{b. Mean stationarity of annual precipitation over China (1959-2018)}

Because 30 years is a widely used climatic time scale (Arguez et al. 2012; WMO 2019), the precipitation period of 1959-2018 is divided into two periods, 1959-88 and 1989-2018. The mean stationarity of the $90 \%$ CL for each grid cell is calculated. Figure 3 presents the results of the $30-\mathrm{yr}$ mean precipitation $(90 \% \mathrm{CL}$ ) for the periods $1959-88$ and $1989-2018$, respectively; $97.47 \%$ of the grid cells are within $90 \%$ CI. Results based on meteorological stations show that $97.97 \%$ of the stations are within $90 \%$ CL (Fig. S2). The grid cells with mean precipitation beyond the $\mathrm{CI}$ are primarily located in northwest China where the annual rainfall is less. The autocorrelation and 30-yr means of all grid cells with 

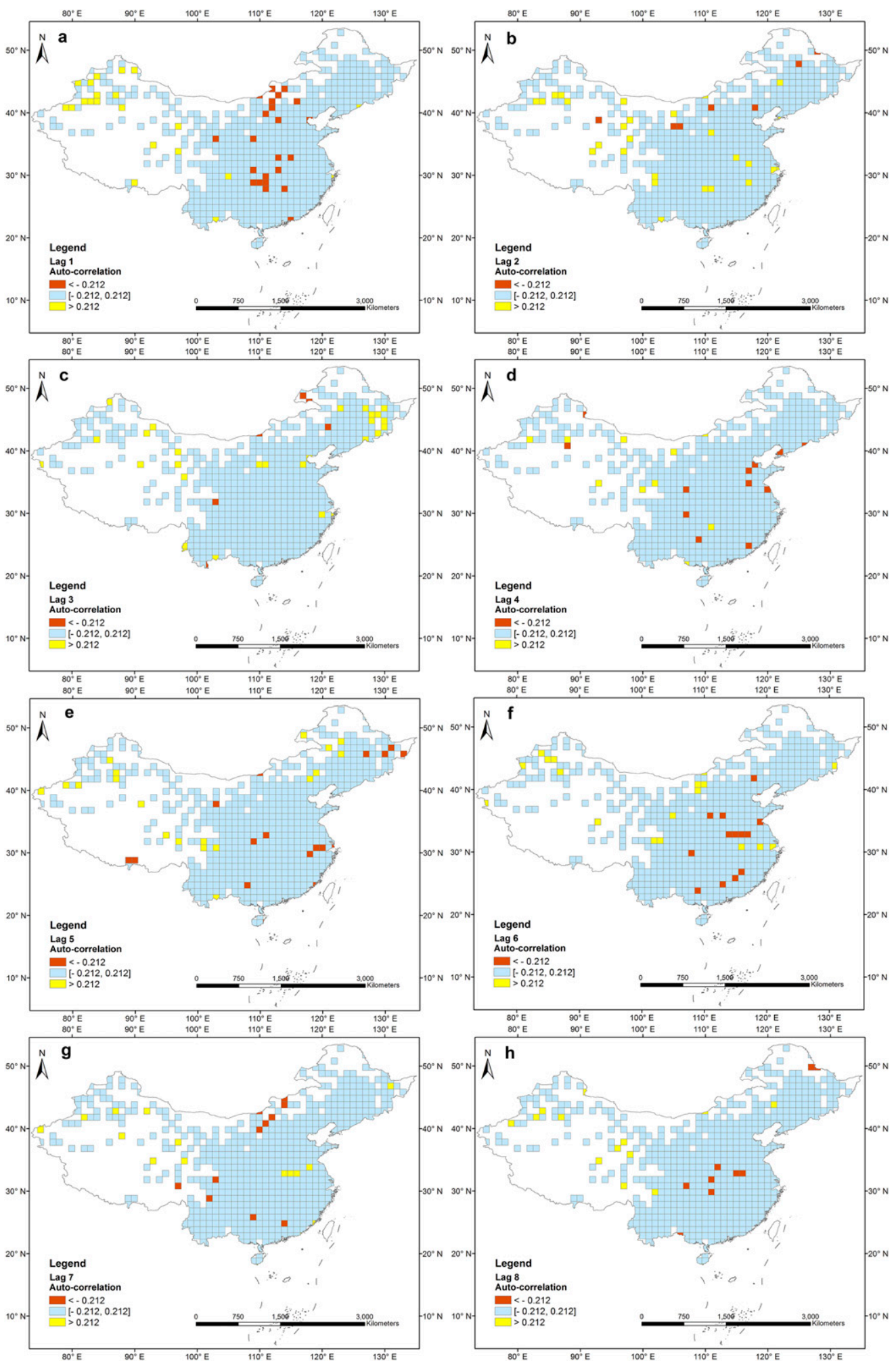

FIG. 2. Analysis of the stationarity of precipitations for 60 years (1959-2018) over China. Autocorrelation for (a)-(h) lags 1-8 for the annual precipitation (1959-2018). Significance values $( \pm 0.212)$ are for the $90 \%$ confidence level (CL), which are thresholds to distinguish grid cells that have lags with autocorrelation indistinguishable from zero (blue) from those showing positive (yellow) and negative (red) lag autocorrelation. 


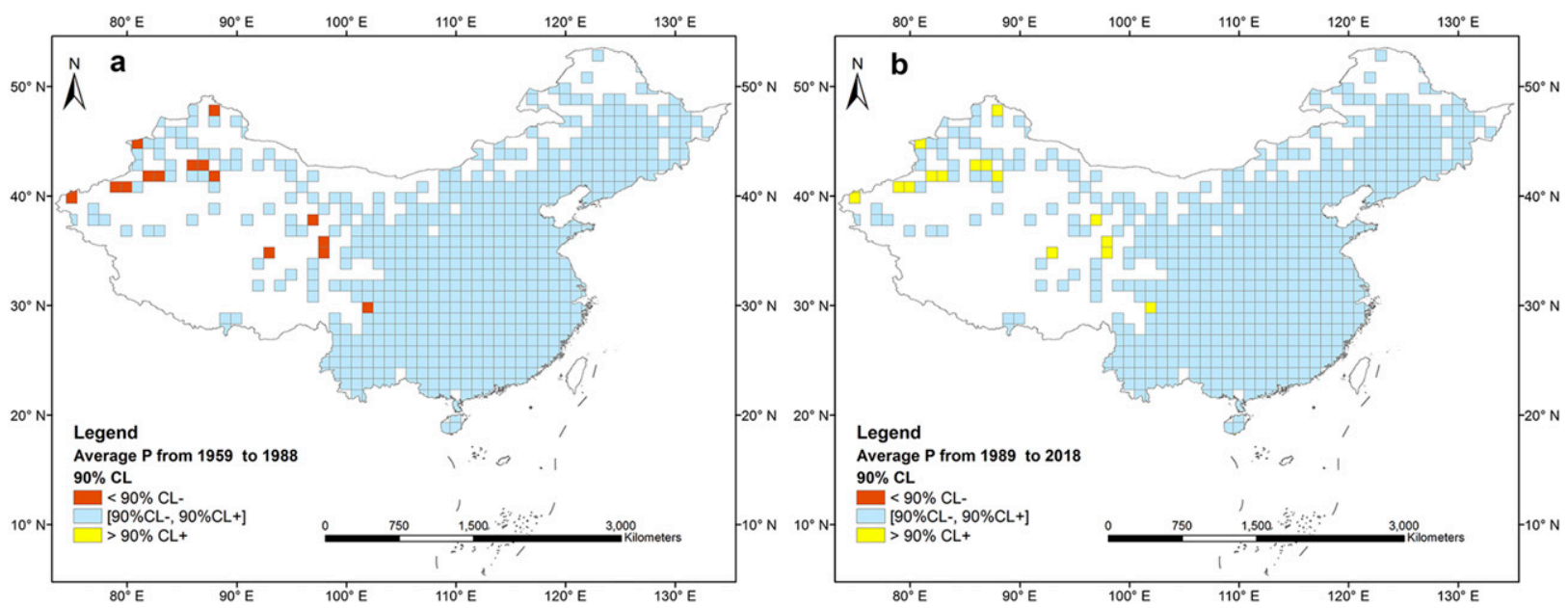

FIG. 3. Results of the 30-yr mean precipitation within the 90\% CL during the period (a) 1959-88 and (b) 1989-2018.

mean precipitation beyond the $90 \%$ CI are further analyzed (Fig. 4 and Fig. S3). Results indicate that the 30 -yr means are almost on the lines of the $90 \%$ confidence limits, and the average value beyond the limit is $\pm 3.78 \mathrm{~mm}$. Figure 2 also shows that the grid cells with autocorrelation larger than $90 \%$ confidence limits are also mainly located in northwest China. Figure 4 and Figure S3 also show their autocorrelation coefficients of lag 1-20.
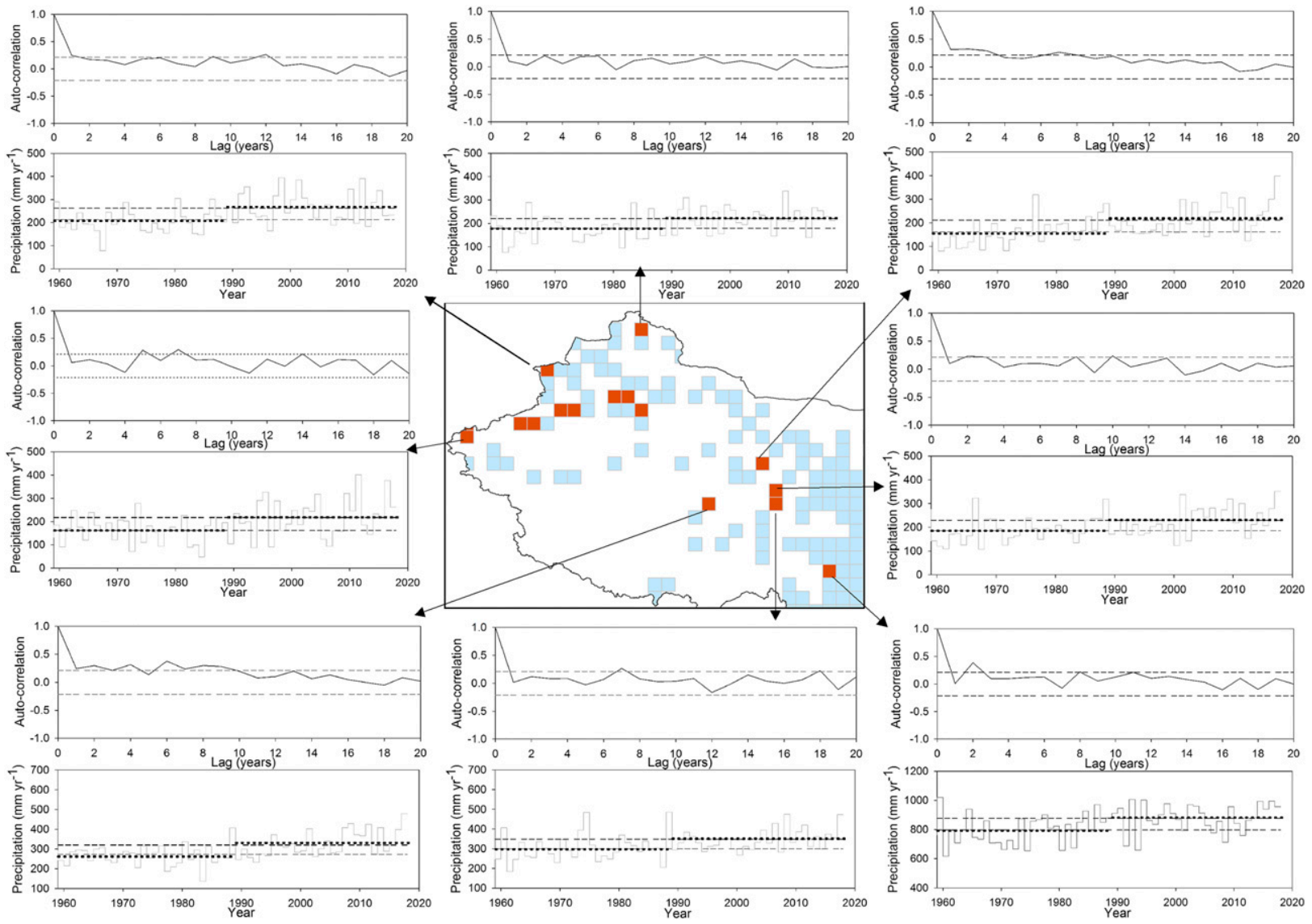

FIG. 4. The grid cells of the 30-yr mean precipitation beyond the $90 \%$ CL over the periods $1959-88$ and 1989-2018. Autocorrelation of precipitation from lags 1-20 with 90\% CL (dashed). Annual precipitation from 1959 to 2018 (vertical step). Averages (dotted line) over 30-yr time periods with $90 \%$ CL (dashed). The analysis of other seven grid cells in the middle are shown in Fig. S3. 


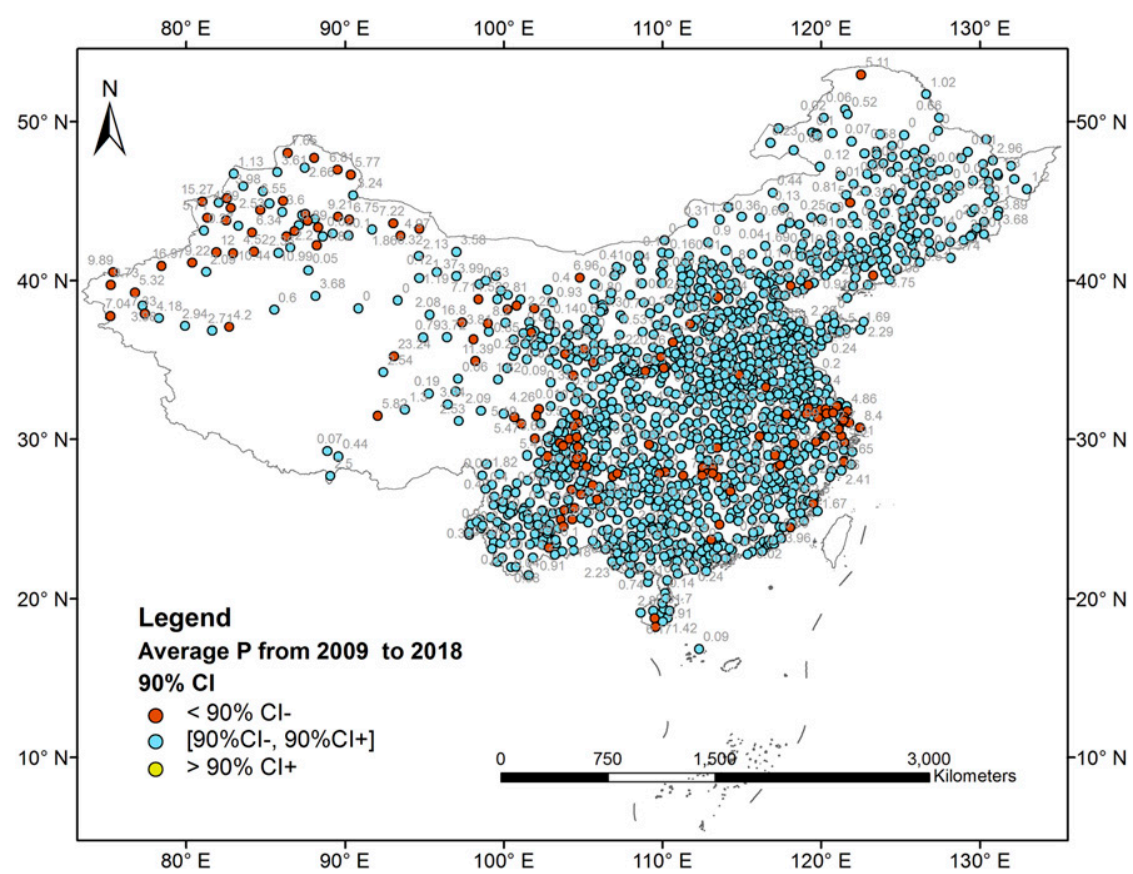

FIG. 5. The significance test for annual precipitation between two $30-y r$ periods. A oneway ANOVA is used, and the blue dot indicates that there is no significant difference $\left[F_{\text {calculated_value }}<F_{\text {table_lookup_value }}=F_{0.05}(1,56)=4.01\right.$, or $\left.P>0.05\right]$ in annual precipitation between the two 30 -yr periods.

It can be seen that the autocorrelation coefficients are indistinguishable from 0 except for several years of lag. Results show that the means of precipitation were stationary and independent over time, indicating first-order stationarity. The climate variables are considered as stationarity if the means remain constant over the climate time scale (Arguez and Vose 2011; Griggs and Noguer 2002; Knox and Kundzewicz 1997; Sun et al. 2018).

Further, the statistical analysis shows that the annual precipitation in the two 30-yr periods has the same distribution, which conforms to the normal distribution. A one-way ANOVA is used to test the significant differences in precipitation between the two 30 -yr periods. The results indicate that there is no significant difference $\left[F_{\text {calculated_value }}<F_{\text {table_lookup_value }}=F_{0.05}(1,56)=4.01\right.$, or $P>0.05]$ in annual precipitation between the two 30 -yr periods at 1281 out of 1427 stations (approximately $89.77 \%$ ); the statistics presented are shown in Fig. 5. Combining the autocorrelation stationarity results (section 3a), we can conclude that the annual precipitation over China has a weakly stationary behavior.

\section{c. Stationarity of long-term precipitation in Beijing and Shanghai}

Based on the annual precipitation observations of Beijing for 200 years (1819-2018) and Xujiahui station in Shanghai for 140 years (1879-2018), the stationarity of long-term annual precipitation is analyzed. The average annual precipitation is $605.32 \mathrm{~mm}$ in Beijing and $1180.90 \mathrm{~mm}$ in Shanghai. The autocorrelation coefficients of two stations with a lag of 1-80 years are calculated. The results show that most of the autocorrelation coefficients are in the $90 \%$ CI (Figs. 6b,e). The 30-yr mean precipitations over six periods in Beijing are within the $90 \% \mathrm{CI}$, as are those over the four periods in Shanghai. The means are constant, and the autocorrelations are in distinguishable from 0 , so the long-term annual precipitation in Beijing and Shanghai depicts stationary behavior.

\section{d. Variations in annual precipitation over China (1999-2018)}

The variations in precipitation in the past 20 years (1999-2018), compared to that in the past 60 years (1959-2018), are analyzed using the method of Sun et al. (2018). Figure 7 shows that $95.23 \%$ of precipitation variations are within the $90 \% \mathrm{CI}$. The average variation in precipitation over China in 30 successive years is $\pm 78.94 \mathrm{~mm}$, which accounts for $9.55 \%$ of the mean annual precipitation. Mean stationarity between 10 successive years is also analyzed (Fig. S4). For the five consecutive 10-yr periods from 1959 to 2008 , more than $91 \%$ of the mean precipitation of the grid cells are within $90 \%$ CL, with an average of $93.70 \%$, and the average of $86 \%$ for $2009-18$. The precipitation for 10 successive 

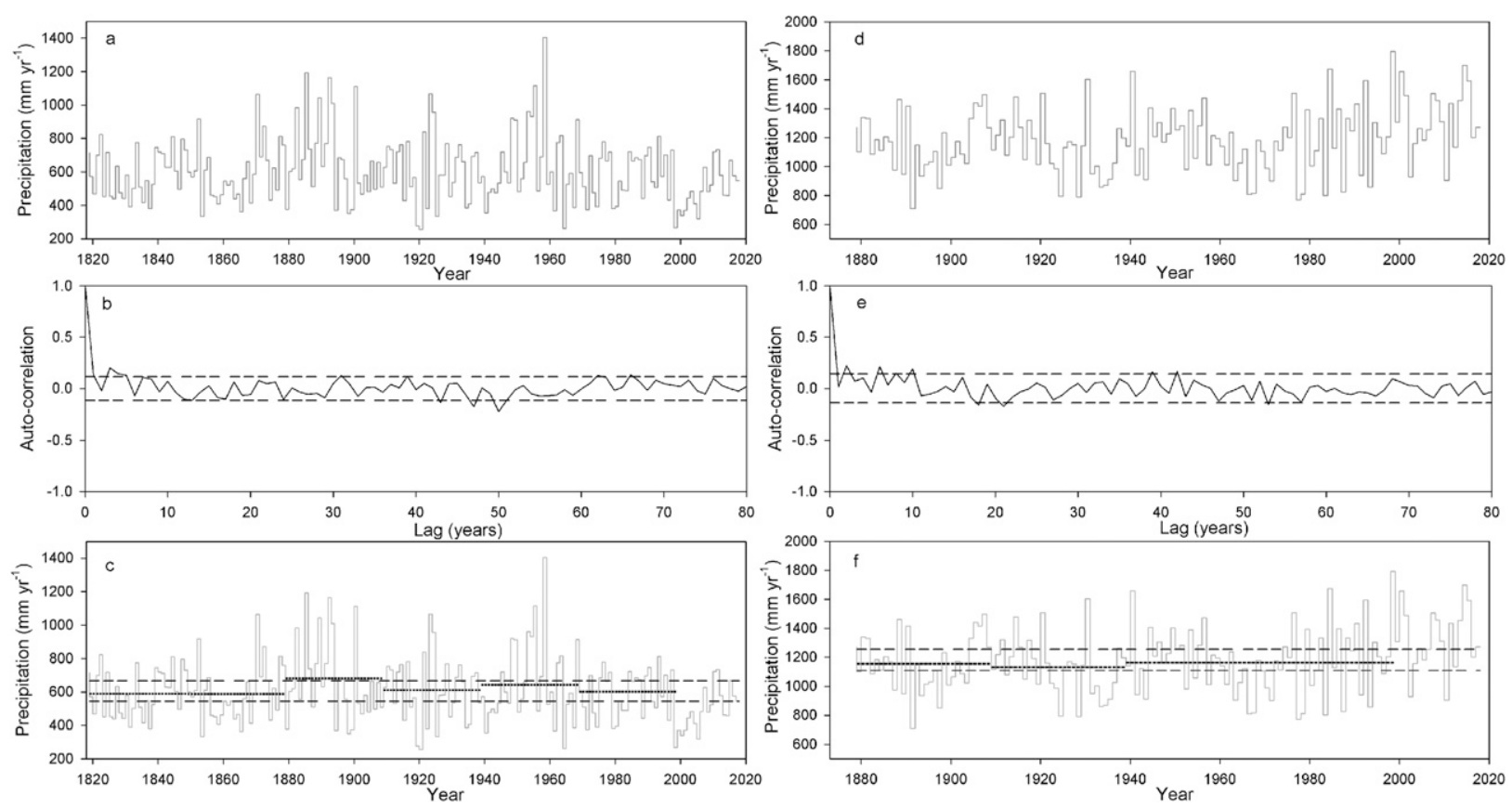

FIG. 6. Annual precipitation data at the Beijing station over 200 years (1819-2018) and Shanghai station over 140 years (1879-2018). (left) Beijing station. (right) Xujiahui station in Shanghai. (a),(d) Annual precipitation. (b),(e) Autocorrelation of precipitation for lag 1-80 with $90 \%$ CL (dashed). Averages (dotted line) over (c),(f) 30-yr time periods with $90 \%$ CL (dashed).

years also exhibits a stationarity behavior, although it does not exhibit a more stable behavior than that occurring over 30 consecutive years. The average variation in precipitation between 10 successive years is $\pm 136.73 \mathrm{~mm}$ over China, which accounts for $16.53 \%$ of the mean annual precipitation. The analysis based on meteorological stations shows similar results to that based on grid cells analysis (Fig. S5).

Stationarity is predicated based on an assumption that the generating process is in equilibrium around an underlying mean and that variance remains constant over time. The stationarity is analyzed by the mean and autocorrelation of annual precipitation time series according to the definition of weak stationarity over China. From what has been analyzed above, the annual precipitation in China exhibits a stationary behavior that is indistinguishable from the stationary stochastic process. This result is consistent with many previous studies conducted on the stationarity of annual precipitation. Sun et al. (2018) found that the annual precipitation showed a stationary behavior over the global land surface and approximately $76 \%$ of it showed little or no change (90\% CL) using the same method. Murphy and Ellis (2014) found stationarity of annual precipitation in watersheds of the Colorado River basin with time series analysis methods and testing criteria established per the statistical definitions of stationarity. Majority of the stationary results are based on annual precipitation; and monthly analysis results have been obtained. Based on analysis techniques including homogeneity tests and anomalies and trend analysis, monthly precipitation series showed such stationary behavior during 18591997 in peninsular Spain (Llasat and Quintas 2004). Mahlstein et al. (2012) estimated the global temperature increase required for precipitation change signal of interannual variability using global climate models and found that the signal of precipitation changes during the wet season was not anticipated in the near future over a widespread region and would occur before the end of this century when the global temperature has increased by $1.4^{\circ} \mathrm{C}$ above $1900-29$ values (Mahlstein et al. 2012). Further, grid cells within $90 \%$ CL show stationary behavior according to the definition of stationarity, while the grid cells outside of the $90 \%$ do not mean that they are nonstationary. Because a significant number of grid cells might be expected to fall outside of a $90 \%$ CI by chance alone (DelSole and Yang 2011; Ivanov et al. 2017; Renard et al. 2008), this aspect needs further analysis.

However, the signal of extreme precipitation change with temperature has been clearly detected, and the precipitation extreme is expected to increase by $7 \%$ per degree warming according to the Clausius-Clapeyron (CC) relation which states that the atmosphere can hold about $6 \%-7 \%$ more water vapor per degree of warming before saturation occurs (Dhakal et al. 2015; Gu et al. 2017; Jakob et al. 2011; Kharin et al. 2007; 


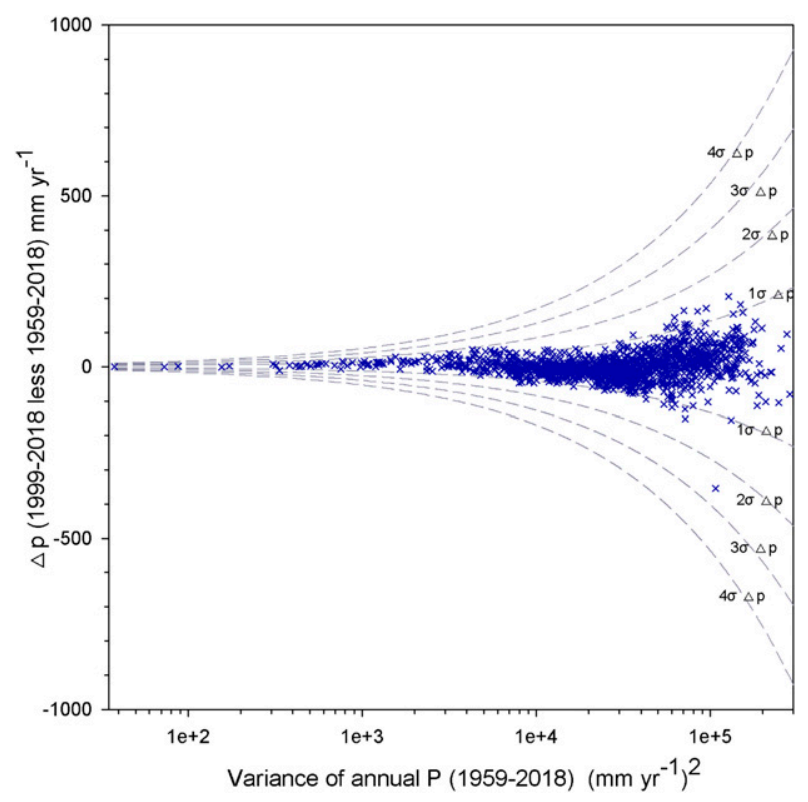

FIG. 7. Testing annual precipitation in recent 20 years (19992018) for significant changes compared to precipitation over the past 60 years (1959-2018). The ordinate shows $\Delta P$, calculated as the difference between mean annual $P$ for 1999-2018 and that for 1959-2018 as a function of the variance of the annual time series (1959-2018) for the observations.

Lewis 2018; Prosdocimi et al. 2014; Seth and Sisson 2011; She et al. 2015; Uboldi and Lussana 2017). Extreme precipitation is expected to increase by $7 \%$ at daily time scales and $14 \%$ at subdaily time scales with $1{ }^{\circ} \mathrm{C}$ increase in temperature in China (Wang et al. 2018). Many studies have reported that extreme precipitation depicts nonstationarity behavior, that is, nonstationarity in the timing of extreme precipitation over China ( $\mathrm{Gu}$ et al. 2017), nonstationarity in intensity, duration and frequency of extreme precipitation over India (Mondal and Mujumdar 2015), nonstationarity in seasonality of extreme precipitation in the state of Maine, located in the northeastern region of the United States (Dhakal et al. 2015), and nonstationarity in annual and seasonal series of extreme precipitation in the United Kingdom (Prosdocimi et al. 2014).

Therefore, it is crucial and feasible to use the historical data of annual precipitation as the basis of water resources application in China. Moreover, the changes in extreme precipitation as well as daily and subdaily precipitation must be considered for improved planning of water-resource engineering.

\section{Conclusions}

Based on daily precipitation observations of 1473 meteorological stations from 1959 to 2018 over China, the Beijing station with 200 years (1819-2018) of data and Xujiahui station in Shanghai with data of 140 years (1879-2018), the stationarity characteristics of annual precipitation are analyzed. A total of 593 efficient grid cells $\left(1^{\circ} \times 1^{\circ}\right)$, containing at least one station each grid, are constructed over China to minimize the statistical deviation caused by the nonuniformity of the distribution of the meteorological station.

Stationarity is analyzed by the mean and autocorrelation of annual precipitation time series according to the definition of weak stationarity. The results of the $30-y r$ mean precipitation ( $90 \% \mathrm{CL}$ ) indicate that $97.47 \%$ of the grid cells are within the $90 \%$ CI over China. The results of precipitation autocorrelation stationarity indicate that $92.24 \%$ of the grid cells for lag 1 autocorrelation coefficient are within $90 \% \mathrm{CI}$, and $93.76 \%-96.12 \%$ for lags $2-8$ over China. The means are constant and the autocorrelations are indistinguishable from 0 ; thus, the annual precipitation over China depicts stationary behavior. Similarly, the mean and autocorrelation of annual precipitation in Beijing for 200 years and Shanghai for 140 years also indicate clear stationary behaviors. The precipitation variations in the past 20 years, compared to those of the past 60 years, over China are analyzed, and $95.23 \%$ of precipitation variations are within the $90 \%$ CI. The average precipitation variations in 30 and 10 successive years are \pm 78.94 and $\pm 136.73 \mathrm{~mm}$, respectively.

The annual precipitation in China exhibits a stationary behavior, which shows that the historical observation data are still of significant value. Moreover the changes in extreme precipitation as well as daily and subdaily precipitation must be considered for improved planning of water-resource engineering.

Acknowledgments. This work was supported by the Strategic Priority Research Program of the Chinese Academy of Sciences (XDA23040504), the National Natural Science Foundation of China (41601035), the National Key Research and Development Program of China (2016YFA0602402, 2016YFC0401401), the Key Programs of the Chinese Academy of Sciences (ZDRWZS-2017-3-1), the Chinese Academy of Sciences (CAS) Pioneer Hundred Talents Program.

\section{REFERENCES}

Arguez, A., and R. S. Vose, 2011: The definition of the standard WMO climate normal: The Key to deriving alternative climate normals. Bull. Amer. Meteor. Soc., 92, 699-704, https://doi.org/ 10.1175/2010BAMS2955.1.

- I. Durre, S. Applequist, R. S. Vose, and T. W. Owen, 2012: NOAA's 1981-2010 U.S. climate normals: An overview. Bull. 
Amer. Meteor. Soc., 93, 1687-1697, https://doi.org/10.1175/ BAMS-D-11-00197.1.

Benoit, L., M. Vrac, and G. Mariethoz, 2018: Dealing with nonstationarity in sub-daily stochastic rainfall models. Hydrol. Earth Syst. Sci., 22, 5919-5933, https://doi.org/10.5194/hess-225919-2018.

Burt, J. E., G. M. Barber, and D. L. Rigby, 2009: Elementary Statistics for Geographers. 3rd ed. The Guilford Press, $653 \mathrm{pp}$.

Cordery, I., R. Mehrotra, and M. J. Nazemosadat, 2007: How reliable are standard indicators of stationarity? Stochastic Environ. Res. Risk Assess., 21, 765-771, https://doi.org/10.1007/ s00477-006-0088-8.

Deb, P., A. S. Kiem, and G. R. Willgoose, 2019: Mechanisms influencing non-stationarity in rainfall-runoff relationships in southeast Australia. J. Hydrol., 571, 749-764, https://doi.org/ 10.1016/j.jhydrol.2019.02.025.

DelSole, T., and X. Yang, 2011: Field significance of regression patterns. J. Climate, 24, 5094-5107, https://doi.org/10.1175/ 2011JCLI4105.1.

Dhakal, N., S. Jain, A. Gray, M. Dandy, and E. Stancioff, 2015: Nonstationarity in seasonality of extreme precipitation: A nonparametric circular statistical approach and its application. Water Resour. Res., 51, 4499-4515, https://doi.org/10.1002/ 2014WR016399.

Griggs, D. J., and M. Noguer, 2002: Climate Change 2001: The Scientific Basis. Contribution of working Group I to the third assessment report of the intergovernmental panel on climate change. Weather, 57, 267-269, https://doi.org/10.1256/ 004316502320517344.

Gu, X., Q. Zhang, V. P. Singh, and P. Shi, 2017: Nonstationarity in timing of extreme precipitation across China and impact of tropical cyclones. Global Planet. Change, 149, 153-165, https:// doi.org/10.1016/j.gloplacha.2016.12.019.

Ivanov, M., K. Warrach-Sagi, and V. Wulfmeyer, 2017: Field significance of performance measures in the context of regional climate model evaluation. Part 2: Precipitation. Theor. Appl. Climatol., 132, 239-261, https://doi.org/10.1007/s00704-0172077-x.

Jakob, D., D. J. Karoly, and A. Seed, 2011: Non-stationarity in daily and sub-daily intense rainfall - Part 1: Sydney, Australia. Nat. Hazards Earth Syst. Sci., 11, 2263-2271, https://doi.org/ 10.5194/nhess-11-2263-2011.

Kharin, V. V., F. W. Zwiers, X. Zhang, and G. C. Hegerl, 2007: Changes in temperature and precipitation extremes in the IPCC ensemble of global coupled model simulations. J. Climate, $\mathbf{2 0}$, 1419-1444, https://doi.org/10.1175/JCLI4066.1.

Khintchine, A., 1934: Korrelationstheorie der stationären stochastischen Prozesse. Math. Ann., 109, 604-615, https://doi.org/ 10.1007/BF01449156.

Knox, J. C., and Z. W. Kundzewicz, 1997: Extreme hydrological events, palaeo-information and climate change. Hydrol. Sci. J., 42, 765-779, https://doi.org/10.1080/02626669709492071.

Kolmogorov, A. N., 1938: A simplified proof of the BirkhoffKhinchin ergodic theorem. Usp. Mat. Nauk, 5, 52-56.

Koutsoyiannis, D., and A. Montanari, 2015: Negligent killing of scientific concepts: The stationarity case. Hydrol. Sci. J., 60 1174-1183, https://doi.org/10.1080/02626667.2014.959959.

Lewis, S. C., 2018: Assessing the stationarity of Australian precipitation extremes in forced and unforced CMIP5 simulations. J. Climate, 31, 131-145, https://doi.org/10.1175/ JCLI-D-17-0393.1.

Llasat, M. C., and L. Quintas, 2004: Stationarity of monthly rainfall series, since the middle of the XIXth century. Application to the case of Peninsular Spain. Nat. Hazards, 31, 613-622, https://doi.org/10.1023/B:NHAZ.0000024894.66869.46.

Mahlstein, I., R. W. Portmann, J. S. Daniel, and S. Solomon, 2012: Perceptible changes in regional precipitation in a future climate. Geophys. Res. Lett., 39, L05701, https://doi.org/10.1029/ 2011 GL050738.

Matalas, N. C., 2012: Comment on the announced death of stationarity. J. Water Resour. Plann. Manage., 138, 311-312, https://doi.org/10.1061/(ASCE)WR.1943-5452.0000215.

McCarl, B. A., X. Villavicencio, and X. Wu, 2008: Climate change and future analysis: Is stationarity dying? Amer. J. Agric. Econ., 90, 1241-1247, https://doi.org/10.1111/j.14678276.2008.01211.x.

Milly, P. C. D., J. Betancourt, M. Falkenmark, R. Hirsch, Z. W. Kundzewicz, D. P. Lettenmaier, and R. J. Stouffer, 2008: Stationarity is dead: Whither water management? Science, 319, 573-574, https://doi.org/10.1126/science.1151915.

, and Coauthors, 2015: On critiques of "stationarity is dead: Whither water management?" Water Resour. Res., 51, 77857789, https://doi.org/10.1002/2015WR017408.

Mondal, A., and P. P. Mujumdar, 2015: Modeling non-stationarity in intensity, duration and frequency of extreme rainfall over India. J. Hydrol., 521, 217-231, https://doi.org/10.1016/ j.jhydrol.2014.11.071.

Montanari, A., and D. Koutsoyiannis, 2015: Modeling and mitigating natural hazards: Stationarity is immortal! Water Resour. Res., 50, 9748-9756, https://doi.org/10.1002/ 2014WR016092.

Murphy, K. W., and A. W. Ellis, 2014: An assessment of the stationarity of climate and stream flow in watersheds of the Colorado River Basin. J. Hydrol., 509, 454-473, https:// doi.org/10.1016/j.jhydrol.2013.11.056.

Nelson, B. L., and F. J. Matejcik, 1995: Using common random numbers for indifference-zone selection and multiple comparisons in simulation. Manage. Sci., 41, 1935-1945, https:// doi.org/10.1287/mnsc.41.12.1935.

Prosdocimi, I., T. R. Kjeldsen, and C. Svensson, 2014: Non-stationarity in annual and seasonal series of peak flow and precipitation in the UK. Nat. Hazards Earth Syst. Sci., 14, 1125-1144, https://doi.org/10.5194/nhess-14-1125-2014.

Renard, B., and Coauthors, 2008: Regional methods for trend detection: Assessing field significance and regional consistency. Water Resour. Res., 44, W08419, https://doi.org/10.1029/ 2007WR006268.

Richardson, T. B., P. Forster, T. Andrews, and O. Boucher, 2018: Drivers of precipitation change: An energetic understanding. J. Climate, 31, 9641-9657, https://doi.org/10.1175/JCLI-D-170240.1 .

Sadegh, M., J. A. Vrugt, C. Xu, and E. Volpi, 2016: The stationarity paradigm revisited: Hypothesis testing using diagnostics, summary metrics, and DREAM (ABC). Water Resour. Res., 51, 9207-9231, https://doi.org/10.1002/2014WR016805.

Seth, W., and S. A. Sisson, 2011: Detection of non-stationarity in precipitation extremes using a max-stable process model. J. Hydrol., 406, 119-128, https://doi.org/10.1016/ j.jhydrol.2011.06.014.

She, D. X., Q. Shao, J. Xia, J. A. Taylor, Y. Zhang, L. Zhang, $\mathrm{X}$. Zhang, and L. Zou, 2015: Investigating the variation and non-stationarity in precipitation extremes based on the concept of event-based extreme precipitation. J. Hydrol., 530, 785-798, https://doi.org/10.1016/j.jhydrol.2015.10.029.

Shumway, R. H., and D. S. Stoffer, 2000: Spectral Analysis and Filtering. Springer, $265 \mathrm{pp}$ 
and 2011: Time Series Analysis and Its Applications. 3rd ed. Springer, $596 \mathrm{pp}$.

Singh, J., H. Vittal, S. Karmakar, S. Ghosh, and D. Niyogi, 2016: Urbanization causes nonstationarity in Indian summer monsoon rainfall extremes. Geophys. Res. Lett., 43, 11 269-11277, https://doi.org/10.1002/2016GL071238.

Sun, F., M. L. Roderick, and G. D. Farquhar, 2018: Rainfall statistics, stationarity, and climate change. Proc. Natl. Acad. Sci. USA, 115, 2305-2310, https://doi.org/10.1073/ pnas. 1705349115 .
Uboldi, F., and C. Lussana, 2017: Evidence of non-stationarity in a local climatology of rainfall extremes in northern Italy. Int. J. Climatol., 38, 506-516, https://doi.org/10.1002/joc.5183.

Wang, H., F. Sun, and W. Liu, 2018: The dependence of daily and hourly precipitation extremes on temperature and atmospheric humidity over China. J. Climate, 31, 8931-8944, https:// doi.org/10.1175/JCLI-D-18-0050.1.

WMO, 2019: Technical Regulations, Volume I - General meteorological standards and recommended practices. WMO Basic Doc. 2, 48 pp., https://library.wmo.int/doc_num.php?explnum_id=10113. 